Tohoku J. Exp. Med., 2001, 195, 43-54

\title{
Glomerular Endothelial Cells Are Maintained by Vascular Endothelial Growth Factor in the Adult Kidney
}

\author{
Yasunori Kitamoto, Motohiro Takeya ${ }^{1}$, Hiroshi Tokunaga and Kimio \\ TOMITA \\ The Third Department of Internal Medicine, and ${ }^{1}$ Second Department of \\ Pathology, Kumamoto University School of Medicine, Kumamoto 860-8556
}

Kitamoto, Y., Takeya, M., Tokunaga, H. and Tomita, K. Glomerular Endothelial Cells Are Maintained by Vascular Endothelial Growth Factor in the Adult Kidney. Tohoku J. Exp. Med., 2001, 195(1), 43-54_Vascular endothelial growth factor (VEGF) is known to maintain endothelial cells of immature vessels and is constitutively expressed in the kidney from the embryo to adult. We tested the hypothesis that VEGF activity is needed to maintain glomerular endothelial cells in the adult. Neutralizing antibody to VEGFl65 was intraperitoneally administered to mice for 3 days to strongly suppress its intrinsic activity. On the fourth day, mice were sacrificed and tissues were examined by light and electron microscopies. Vascular casts of renal vessels were observed by a scanning electron microscopy. Distribution of the administered antibody and expressions of VEGF and Flk-1 were examined immunohistochemically. The suppression of endogenous VEGF activity caused swelling and vacuolation of endothelial cells and obstruction of capillaries in the glomerulus. Other tissues were not impaired significantly. The administered antibody was specifically localized to the glomerulus, and was found more predominantly in the juxta-medullary than in the cortical glomerulus. This pattern of antibody deposition was similar to that of Flk-1. VEGF expression in the glomerulus was compensatively elevated by the antibody treatment. These results show that demand for VEGF signaling in the glomerulus is much higher than in other tissues, probably to protect its endothelial cells against high tension for blood filtration. This demand may be fulfilled by enriched signaling through the Flk-1 in the glomerulus. $—$ developed kidney; endogenous VEGF; neutralizing antibody; glomerular structure; Flk-1

(C) 2001 Tohoku University Medical Press

Received June 11, 2001; revision accepted for publication September 26, 2001.

Address for reprints: Dr. Yasunori Kitamoto, The Third Department of Internal Medicine, Kumamoto University School of Medicine, 111 Honjo, Kumamoto 860-8556, Japan.

e-mail: yasunori@kaiju.medic.kumamoto-u.ac.jp 
Each human kidney contains approximately one million glomeruli, where ultrafiltration of the blood proceeds at fenestrated and coiled capillaries between afferent and efferent arterioles. Thus, endothelial cells in the glomerulus are continuously exposed to much higher tension (Brenner et al. 1971) and tends to be injured more often than those in any other capillaries. Although support and repair mechanisms should exist to maintain the glomerular endothelial cells, they have not yet been clarified on a molecular basis.

Vascular endothelial growth factor (VEGF) has been shown to mediate various types of neovascularization (Kim et al. 1993; Takeshita et al. 1994; Carmeliet et al. 1996; Ferrara et al. 1996, 1998; Gerber et al. 1999; Sato et al. 2000) as well as increase vascular permeability (Senger et al. 1983; Connolly et al. 1989). In neonatal mice, VEGF has been shown to mediate the development of several uniquely differentiated vascular structures, which include the renal glomerulus (Kitamoto et al. 1997; Kloth et al. 1998; Gerber et al. 1999; Tufro et al. 1999), liver sinusoid (Gerber et al. 1999), and pulmonary alveolus (Gerber et al. 1999). VEGF was also shown to protect the endothelial cell from apoptosis in newly-formed vessels of retinal (Alon et al. 1995) and tumor (Benjamin and Keshet 1997) tissues, respectively. In adult mice, VEGF is expressed by epithelial cells in various tissues (Ferrara and DavisSmyth 1997) including the glomerulus and tubule (Brown et al. 1992; Bacic et al. 1995; Gröne et al. 1995; Simon et al. 1995), and receptors Flt-1 and Flk-1 are expressed on endothelial cells of the glomerular and peritubular capillaries (Simon et al. 1995) in the kidney. More recently, Flk-l messages were expressed in the glomerular capillary and Flt-1 messages in the peritubular capillary, respectively (Marti and Risau 1998). As Flk-1 mediates important functions of VEGF (Ferrara 1999), VEGF might play a critical role in the developed glomerulus, too. However, the role of VEGF in the developed kidney has not yet been defined. When endo-genous VEGF activity was partially suppressed in adult animals by soluble fit-1 receptor (Gerber et al. 1999) or aptamer (Ostendorf et al. 1999), histological changes in kidneys were not clear. Roles of VEGF in renal diseases are not clear, either. In glomerulonephritis, VEGF was expressed in glomerular epithelial (Gröne et al. 1995; IruelaArispe et al. 1995; Shulman et al. 1996; Bailey et al. 1999) and mesangial (Iruela-Arispe et al. 1995) cells and may be involved in repair of injured glomeruli (Iruela-Arispe et al. 1995; Ostendorf et al. 1999). Recent report shows that recombinant VEGF accelerates renal recovery in experimental thrombotic microangiopathy (Kim et al. 2000). In chronic renal failure patients, urinary excretion of VEGF elevates as renal function falls (Kitamoto et al. 2001).

We administered a high dose of antibody to adult mice to suppress endogenous VEGF activity as much as possible, and examined histological changes of their kidneys.

\section{Materials AND Methods}

Approval for animal studies was obtained from the Ethics Committee for Animal Experiments at the Kumamoto University.

Reactivity of the neutralizing antibody with mouse VEGF

Seventy-five ng of recombinant mouse VEGF120 (Genzyme Techne, Minneapolis, MN, USA), recombinant mouse VEGF164 (Strathman Biotech, Hannover, Germany) and recombinant human VEGF165 (Pepro Tech, Inc., Rocky Hill, NJ, USA) were applied to $12.5 \%$ SDS-polyacrylamide gel, electrophoresed and subjected to immunoblotting using the rabbit polyclonal neutralizing antibody (Genentech Inc., South San Francisco, CA, USA) to recombinant human VEGF165. 


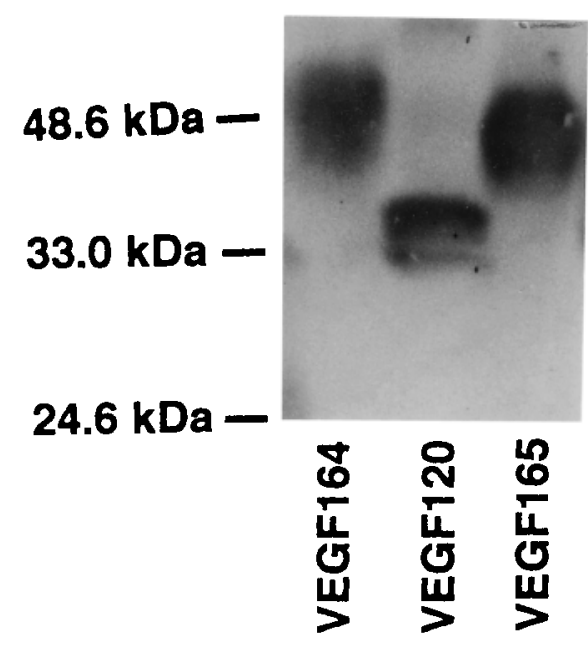

Fig. 1. Immunoblot analysis of the neutralizing antibody. Clear bands were observed which shows that the antibody reacted with mouse VEGF164 and VEGF120 as well as human VEGF165.

Suppressing endogenous activity of $V E G F$

Male 6-week-old ICR mice and AKR mice were used for this study. As AKR mice are deficit of the 5th component of complement (Okada and Okada 1978), activation of the later components of the complement system was excluded in them. The rabbit polyclonal antibody described above was prepared as an antiserum and one $\mathrm{ml}$ of the antibody neutralized $1.25 \mu \mathrm{g}$ of mitotic activity of VEGF 165 according to in vitro assay ( $\mathrm{Kim}$ et al. 1992) using human umbilical endothelial cells. The antibody was administered to mice intraperitoneally under ether anesthesia every day, at fifty $\mu \mathrm{L} / \mathrm{g}$ body weight per dose, for three days. As control, normal rabbit serum (Organon Teknika-Cappel, Durham, NC, USA), instead of the antibody, was injected to their littermates using the same protocol. Mice were sacrificed under anesthesia on the 4 th experimental day and tissues were histologically studied by light microscopy with regular- and immuno-stainings as well as by electron microscopy. Blood and urine were collected before the first injection and at sacrificing the animal, respectively.
Blood cells were counted and Giemsa staining of the blood cells was performed. Serum levels of creatinine, urea nitrogen, $\mathrm{Na}, \mathrm{K}$ and $\mathrm{Cl}$ were measured. Urine was examined for hematuria, and its creatinine and $\mathrm{Na}$ concentrations were measured.

\section{Routine histology and immunohistochemistry}

Tissues were ordinarily fixed with $4 \%$ paraformaldehyde in $0.1 \mathrm{~mol} /$ liter phosphate buffer or Bouin's solution and embedded in paraffin. Tissues were also rapidly frozen in liquid nitrogen. Four $-\mu \mathrm{m}$ Paraffin sections were stained with hematoxylin and eosin. Immunohistochemistry was performed on $8-\mu \mathrm{m}$ paraffin sections or $8-\mu \mathrm{m}$ frozen sections. To detect localization of the administered antibody, frozen sections were fixed in acetone for $10 \mathrm{~min}$, and then incubated for 2 hours with a peroxidase-conjugated goat polyclonal antibody against rabbit $\operatorname{IgG}$ ( $1: 100$; Organone TeknikaCappel). Immunoactivity was visualized with peroxidase reaction for $3,3^{\prime}$-diaminobenzoic tetrahydrochloride (DAB) and $\mathrm{H}_{2} \mathrm{O}_{2}$ solution. Paraffin sections were dewaxed, treated for 20 minutes with $1 \% \mathrm{H}_{2} \mathrm{O}_{2}$ /methanol, and incubated overnight at $4{ }^{\circ} \mathrm{C}$ with a goat polyclonal antibody against human VEGF165 (1:300; R\&D Systems, Inc., Minneapolis, MN, USA). These sections were processed further by avidinbiotin-complex peroxidase method (Vector Laboratories, Inc., Burlingame, CA, USA) and immunoactivity was visualized with DAB.

\section{Number of red cells per glomerular area}

Red cells in glomeruli of antibody-treated and control mice were counted, respectively. Twenty-two glomeruli were selected from the both renal cortex and medulla of each mouse and photographed. Red cells in a glomerular area excluding a vascular pole was counted by two individuals independently. The average of two counts was used as a data. Glomerular area was quantitated by weighing a photographic paper of the area excluding a vascular 
pole. The count was divided by the weight to calculate the number of red cells per glomerular area and the mean value of the control mice was arbitrarily defined as 100\%.

\section{Detecting apoptotic cells}

Apoptotic cells were detected by staining new 3 '-OH DNA ends generated by DNA fragmentation using the Apop Tag in situ apoptosis detection kit (Oncor, Inc., Gaithersburg, MD, USA).

\section{Electron microscopy}

Small blocks of fresh kidney were ordinarily fixed with $2.5 \%$ glutaraldehyde for 60 minutes, washed with $0.1 \mathrm{~mol} /$ liter cacodylate buffer ( $\mathrm{pH}$ 7.4), and fixed further with $1 \%$ osmium tetroxide for 1 hour. Then samples were dehydrated through a graded series of ethanols, and embedded in epoxy resin. Ultrathin sections were examined by an electron microscope, H-7500 (Hitachi, Tokyo), with counterstaining by uranyl acetate and lead citrate.

\section{Microcorrosion casts of the blood vessel}

A male 6-week-old AKR mouse was injected with the antibody to VEGF according to the same protocol as described previously in this section and endogenous VEGF activity was suppressed. As a control, normal rabbit serum was injected to a littermate. On the 4 th experimental day, the mice were anesthesized, injected with papaverin, perfused with saline, perfusionfixed with a phosphate buffered $0.1 \%$ glutaraldehyde, and injected with Batson's \#17 methylmethacrylate (Polysciences, Inc., Warrington, PA, USA) through the thoracic aorta. The resin-injected kidneys were harvested and bisected with a razor blade and corroded in a hot $20 \% \mathrm{NaOH}$ solution. Vascular casts were investigated with a scanning electron microscope (JSM-6400F, JEOL, Akishima) at an acceleration voltage of $15 \mathrm{kV}$.

\section{Distribution of Flk-1 in different tissues}

A six-week-old AKR mouse without receiving any treatment was anesthesized and various organs including the kidney, liver, heart, lung and skeletal muscle were harvested. Tissues were fixed in $4 \%$ paraformaldehyde overnight at room temperature, embedded in polyester wax (BDH Laboratory Supplies, Poole, England) at $40^{\circ} \mathrm{C}$ and sectioned at $8 \mu \mathrm{m}$. An anti-Flk-1 antibody (AVAS12), rat anti-mouse monoclonal (Kataoka et al. 1997), was used as the primary antibody and was reacted with horseradish peroxidase-conjugated anti-rat Ig antibody (Biosource International, Camarillo, CA, USA). Immunoactivity was visualized with $\mathrm{DAB}$ and $\mathrm{H}_{2} \mathrm{O}_{2}$ solution for peroxidase reaction.

\section{Statistics}

All values were shown as mean \pm S.D. and subjected to ANOVA and Fisher's analysis for comparison between two groups.

\section{RESULTS}

Reactivity of the neutralizing antibody

As shown in Fig. 1, rabbit polyclonal neutralizing antibody raised aganinst recombinant human VEGF165 reacted with mouse recombinant VEGF120 and VEGF164, too.

\section{Blocking of endogenous VEGF activity}

There were no macroscopical differences between antibody-treated and control mice. Histologically, fewer red cells were observed in glomeruli of antibody-treated mice than in those of control mice (Fig. 2). Relative number of red cells per glomerular area was significantly $(p<0.01)$ fewer in the antibodytreated mice $(57 \pm 22 \%)$ than control mice $(100 \pm 34 \%$ ) (Fig. 3). The decrease of red cell counts in the glomerulus suggested that glomerular capillaries were impaired by the antibody treatment. Electron micrographs showed swollen endothelial cells with cytoplasmic vacuoles 

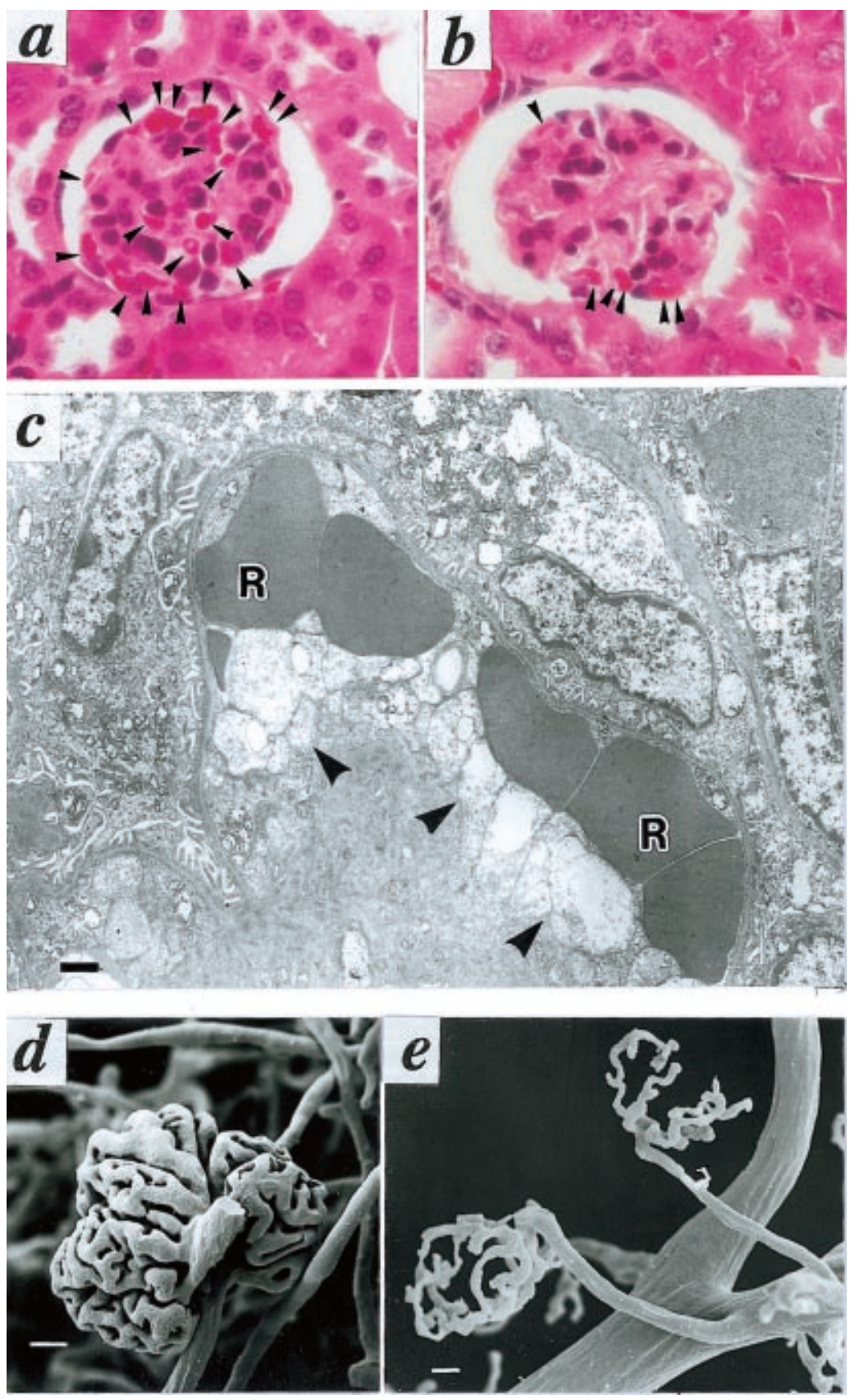

Fig. 2. (a)-(c) Morphological changes of glomeruli by suppressing endogenous activity of VEGF in AKR mice. (a), (b) In light microscopy, there were fewer red cells (arrowheads) in the glomerulus of the antibody-treated (b) as compared with the control (a) mice. (Hematoxylin \& Eosin stain, $\times 160$ ). (c) Transmission electronmicrograph of a glomerulus of the antibodytreated mouse. An endothelial cell is vacuolated (arrowheads), occupying most of the capillary lumen and compressing red cells (R). A scale bar indicates $1 \mu \mathrm{m}$. (d), (e) Scanning electron micrographs of vascular casts of the kidney. The capillary lumen of the glomerulus in the antibody-treated mouse (e) was narrower as compared with the control (d) and interrupted. Lumina of arterioles and arteries were intact and their nuclear imprints were preserved well in the antibody-treated as well as control animals. Scale bars indicate $10 \mu \mathrm{m}$. 


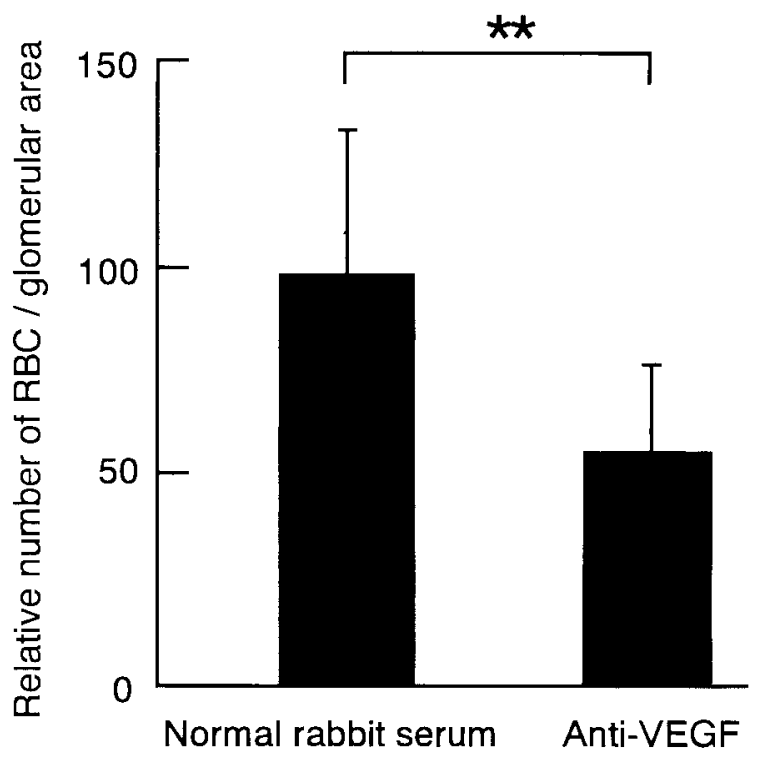

Fig. 3. Number of red cells in the glomerulus changes by administrating the neutralizing antibody. Forty-four glomeruli of control and antibody-treated mice, respectively, were used for counting red cells. In the antibody-treated mice, number of red cells in the glomerulus decreased $\left({ }^{* *} p<\right.$ 0.01 ).

in glomerular capillaries of the antibody-treated mouse (Fig. 2c). No significant morphological changes were observed in mesangial cells, podocytes, or Bowman's capsular epithelial cells. Neither electron-dense deposits nor inflammatory cells were observed in glomeruli of the antibody-treated mouse. No different results were observed between experiments using the ICR and the AKR mice. When microcorrosion casts of renal vessels were examined, normally-shaped glomerular casts occupied $13 \%$ and $71 \%$ of the observed glomeruli in the antibody-treated and control mice, respectively (Figs. $2 \mathrm{~d}$ and $2 \mathrm{e}$ ). The capillary lumen was compressed and interrupted halfway in most of the glomeruli of the antibody-treated mouse (Fig. 2e), although luminal surfaces of arteries and arterioles seemed to be intact in both control (Fig. 2d) and antibody-treated mice. Thus, glomerular capillaries were affected selectively among renal tissues of the antibody-treated mouse. Light-microscopically, there were no changes in the vessels of the brain, heart, lung, liver, adrenal gland, stomach, small and large intestines, and testes (data not shown). There were no significant changes either for counts or morphologies of peripheral blood cells. There were also no changes in serum level of creatinine, urea nitrogen, $\mathrm{Na}, \mathrm{K}$ and $\mathrm{Cl}$ by the antibody treatment. There was no hematuria and no changes in protein and $\mathrm{Na}$ excretions into urine by the antibody treatment, either.

\section{Localization of the antibody}

The administered anti-VEGF antibody was detected specifically in glomeruli of the antiVEGF-treated mouse (Fig. 4b). The staining pattern of the antibody was unlikely to be associated with basement membrane (data not shown), as previously reported (Kitamoto et al. 1997). No significant staining was observed in any other tissues in the kidney. In the control mouse, injected with normal rabbit serum, no IgG was detected in the kidney (Fig. 4a). Neither tissues of the adrenal gland nor the liver were stained (data not shown).

\section{Apoptotic cells in the kidney}

There were no difference either in the occur- 


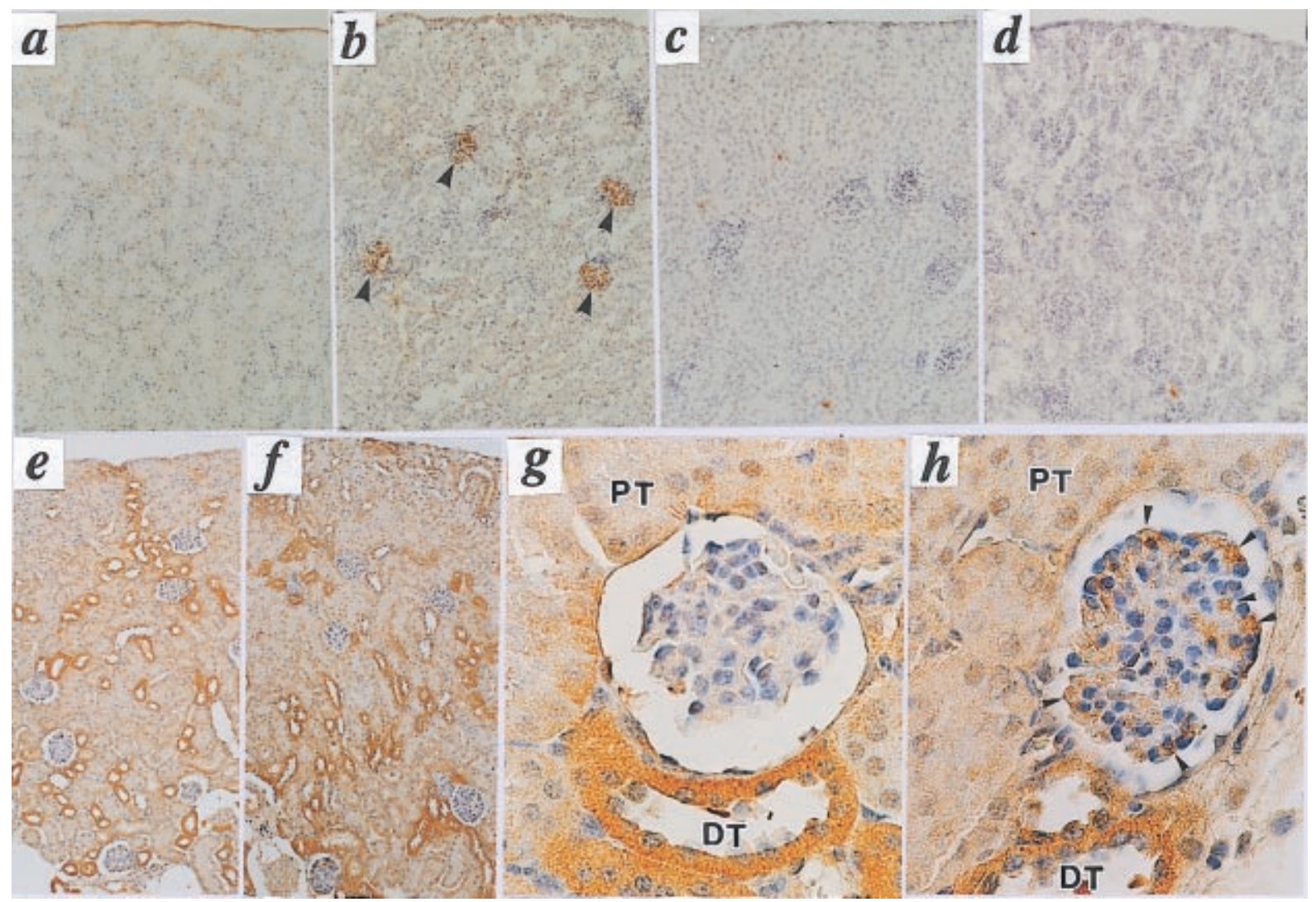

Fig. 4. (a) (h) Detection of the administered antibody, apoptotic cells and VEGF expression in AKR mice. (a), (b) Administered antibody was clearly detected in glomeruli of the antibodytreated mouse (arrowheads) (b), but not of the control (a). (c), (d) There were no significant differences between the antibody-treated (d) and control (c) mice in occurrence or distribution of apoptotic cells in the kidney. (e) (h) VEGF expressions in control (e), (g) and the antibody-treated (f), (h) kidneys. (e), (f) The expression in tubules did not change by the antibody treatment. (g) In the control mouse, VEGF expression was clear in distal tubules (DT) but faint in proximal tubules (PT) and negligible in glomerular cells. (h) In the antibody-treated mouse, VEGF expression was up-regulated in glomerular epithelial cells (arrowheads). The expression in proximal (PT) or distal tubules (DT) did not change by the antibody treatment. (a) (d) $\times 25$; (e),(f) $\times 16$; (g),(h) $\times 160$.

rence or in the distribution of apoptotic cells between the antibody-treated (Fig. 4d) and control (Fig. 4c) mice.

\section{VEGF expression in the kidney}

As shown by lower magnification (Fig. 4f), VEGF expression in renal tubules did not significantly change by the antibody treatment. Contrarily, VEGF expression was up-regulated in glomerular epithelial cells by the antibody treatment (Fig. 4h) as shown by higher magnification.

\section{Expression of Flk-1 in normal mouse tissues}

Flk-1 was selectively expressed at endothelial cells in renal glomeruli of the mouse (Figs. $5 a-5 c)$. The expression level was higher in juxta-medullary than in cortical glomeruli (Figs. 5a and 5b). No significant expressions were observed in the liver, heart, lung, and skeletal muscle (Figs. 5d-5g).

\section{DISCUSSION}

VEGF is essential for vessel formation 


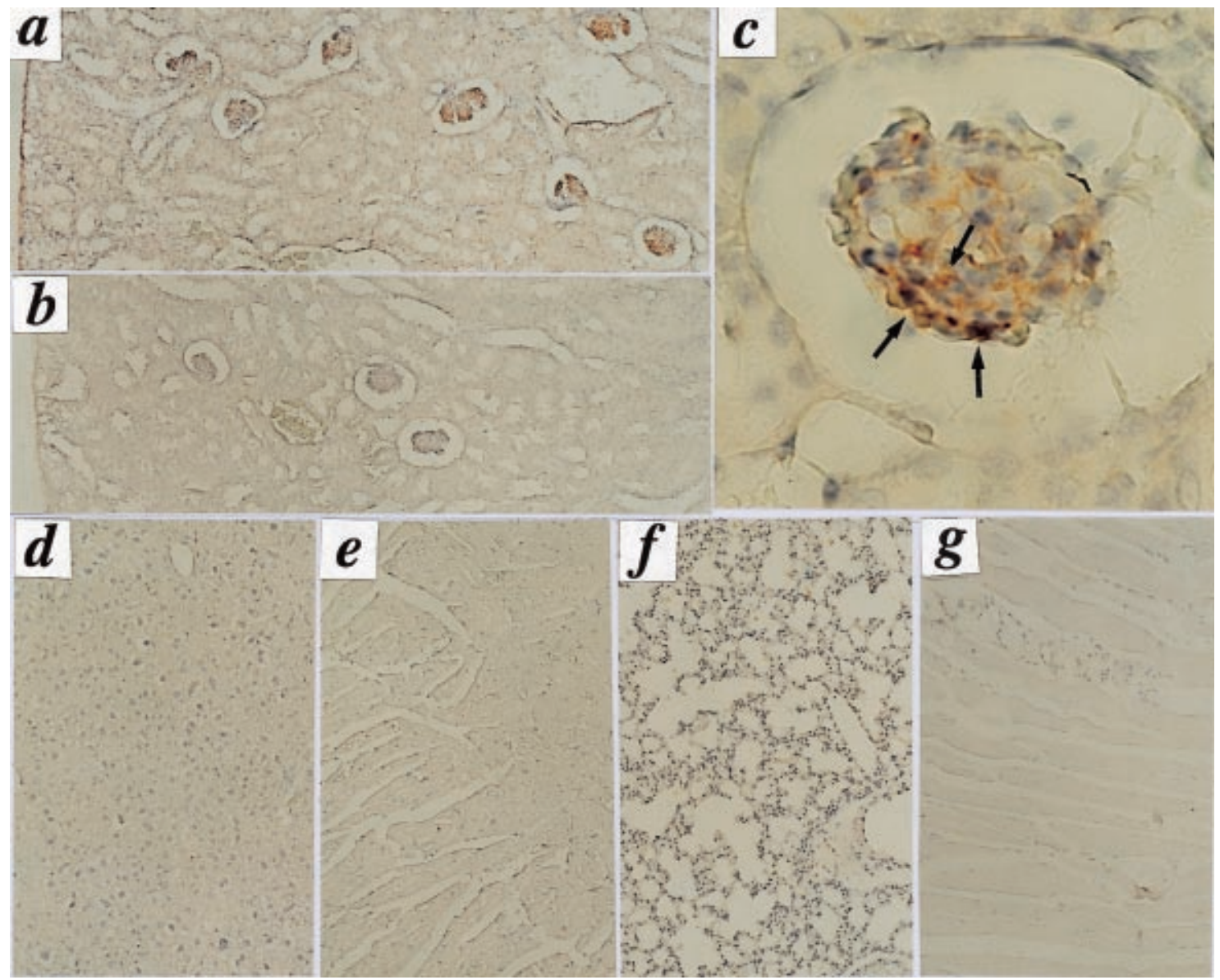

Fig. 5. (a)-(g) Immunohistochemistry showing selective expression of Flk-1 in the renal glomerulus of the AKR mouse. (a) In the kidney, Flk-1 is expressed in the glomerulus. The expression is higher in the juxta-medullary than in the cortical glomerulus. (b) Control for staining without primary antibody. (c) Flk-1 is expressed at glomerular endothelial cells (arrows). The expression is not clear in the liver (d), heart (e), lung (f) or skeletal muscle (g). (a), (b), (d), (e), (f), (g) $\times 25$; (c) $\times 200$.

(Carmeliet et al. 1996; Ferrara et al. 1996) as well as maintenance of newly-formed vessels (Alon et al. 1995; Benjamin and Keshet 1997). In the developing kidney, it mediates glomerular formation (Kitamoto et al. 1997; Kloth et al. 1998; Gerber et al. 1999; Tufro et al. 1999). Although VEGF and its receptors are constitutively expressed in the glomerulus after kidney development (Brown et al. 1992; Bacic et al. 1995; Gröne et al. 1995; Simon et al. 1995), its function in the adult kidney has not yet been clarified.

This is the first report showing the role of VEGF in vivo to maintain the glomerular struc- ture in the adult kidney. In this study, we used a large amount of the anti-VEGF neutralizing antibody, which was shown to react with mouse VEGF120 and VEGF164 by immunoblotting. The antibody was reported to suppress glomerular development in newborn mice (Kitamoto et al. 1997). When the antibody was administered, red cells in the glomerulus decreased (Figs. 2b and 3) and endothelial cells in the glomerulus were swollen and vacuolated (Fig. 2c). According to the observation of vascular casts, the luminal space of the glomerular capillary was narrowed and interrupted (Fig. 2e), which probably decreased red cell 
counts in the glomerulus. Interestingly, changes were restricted to the glomerulus and were not observed in the other tissues examined. This specific action of the antibody was accompanied by its specific localization to the glomerulus (Fig. 4b). The distribution pattern of the antibody was very similar to that of Flk-1 (Fig. 5a), which mediates most of the important functions of VEGF (Ferrara 1999). It is assumed that a large number of VEGF molecules were neutralized by the antibody, but some of the rest molecules escaped, bound themselves first to the Flk-l receptor in the glomerulus and thereafter to the antibody. Thus, inhibition of the VEGF activity was significant but not complete, and localization of the antibody overlapped with that of the Flk-1. As no change was observed in glomeruli of the mice treated by normal rabbit serum, non-specific contribution of the serum to the glomerular change is less likely. Immune complex deposits were not recognized in the glomerulus. As AKR mice are deficit of the 5th component of complement protein (Okada and Okada 1978 ), contribution of the activation of later components of the complement system to the change can be excluded as well. Since there was no significant change in renal function judging from examinations of blood and urine, it is less likely that the glomerular changes were caused by renal dysfunction.

In the antibody-treated mouse, VEGF expression in the glomerular epithelial cell was clearly up-regulated (Fig. 4h), possibly due to tissue hypoxia (Shweiki et al. 1992) resulting from interrupted glomerular circulations. In a previous report (Gerber et al. 1999) using newborn mice, histological changes distributed broadly in renal glomeruli, pulmonary alveoli and hepatic sinusoids. The demand for VEGF activity in immature vessels of newborn mice may be much more than that in mature vessels of adult mice.

Judging from both much higher susceptibility of the glomerulus to deficient VEGF activity and much more abundant expression of Flk-1 in the glomerulus than in other tissues, we can say that the glomerulus requires much more VEGF signaling than other tissues examined. VEGF signaling through Flk-1 may be essential to support endothelial cells so that they can maintain the glomerular structure for blood filtration under high tension. This hypothesis is supported by the fact that the juxtamedullary glomerulus, exposed to a higher blood pressure (Ericson et al. 1982), showed a higher Flk-1 expression than the cortical glomerulus, exposed to a lower pressure (Fig. 5). The mechanism which maintains the high expression of the Flk-1 in the glomerulus is so far unknown. Vessels lacking pericytes might be more susceptible to a deficent VEGF signaling than vessels covered with pericytes (Benjamin et al. 1998). In the developed glomerulus, endothelial cells are only partially covered by mesangial cells, which are a kind of pericyte. This might be another reason why glomerular endothelial cells still highly depend on VEGF signaling even after their development.

Apoptotic cells did not increase by the antibody treatment (Figs. $4 \mathrm{c}$ and 4d). Morphological changes of the glomerular endothelial cell of the antibody-treated mouse were regarded as degeneration, and different from the apoptosis (Alon et al. 1995; Benjamin et al. 1997) induced by suppressing VEGF activity in the newly-formed vessels. According to a previous report (Gerber et al. 1999), when VEGF was suppressed in newborn mice, the glomerulus was impaired but apoptosis of the glomerular cells did not increase. As the glomerulus is a uniquely differentiated structure, signaling pathways in its endothelial cells might not be exactly the same as those of endothelial cells in other tissues. Morphological changes, including swelling and vacuolation of the endothelial cell, might have developed by an interruption of the unrelated signaling to apoptosis. Alternately, blocking of the signaling was not 
enough strong to cause apoptosis. It is also possible that apoptotic cells were detached from the vessel wall and not detected.

In the developed glomerulus, endothelial cells shield mesangial and epithelial cells from the blood. If they are injured, mesangial and epithelial cells are exposed to physical, chemical and biological stresses from the blood. As endothelial cells regulate blood clotting and platelet activation, injury of glomerular endothelial cells could cause local as well as systemic thrombotic disorders including TTP/HUS, where administration of VEGF accelerates a repair of injured glomeruli probably through NO generation (Kim et al. 2000). As endothelial cells regulate glomerular circulation by secreting vasoactive substances including NO (Tolins et al. 1990; Ito et al. 1993) and endothelin (Miller et al. 1989), endothelial injury of the glomerulus could threaten its functional and structural integrities. Therefore, there should be a supporting system for the glomerular endothelial cells, and it is highly plausible that VEGF signaling to endothelial cells plays a key role in this system.

In conclusion, VEGF signaling is considered a major supporting mechanism of the glomerulus in the adult kidney.

\section{Acknowledgments}

This work was partially supported by a Grantin-Aid for Scientific Research in Japan (11671040). We thank Dr. Napoleone Ferrara and Dr. Nobuyuki Takakura for their generous gifts of anti-VEGF neutralizing antibody and anti-Flk-1 antibody, respectively. We thank Miss Noriko Teramoto, Miss Yasuyo Hayashida and Mr. Takashi Kumagai for technical assistance. We also thank Dr. Kenichi Iyama, Dr. Hidechika Okada, Dr. Qingyu Wu, Dr. J. Evan Sadler, Dr. Kenji Miyamoto and Prof. Judith Yoneoka for helpful discussions.

\section{References}

Alon, T., Hemo, I., Itin, A., Pe'er, J., Stone, J. \& Keshet, E. (1995) Vascular endothelial growth factor acts as a survival factor for newly formed retinal vessels and has implications for retinopathy of prematurity. Nature Med., 1, 1024-1028.

Bacic, M., Edwards, N.A. \& Merrill, M.J. (1995) Differential expression of vascular endothelial growth factor (vascular permeability factor) forms in rat tissues. Growth Factors, 12, 11 15.

Bailey, E., Bottomley, M., Westwell, S., Pringle, J.H., Furness, P.N., Feehally, J., Brenchley, P.E.C. \& Harper, S.J. (1999) Vascular endothelial growth factor mRNA expression in minimal change, membranous, and diabetic nephropathy demonstrated by non-isotopic in situ hybridisation. J. Clin. Pathol., 52, 735738 .

Benjamin, L.E. \& Keshet, E. (1997) Conditional switching of vascular endothelial growth factor (VEGF) expression in tumors: induction of endothelial cell shedding and regression of hemangioblastoma-like vessels by $\mathrm{VEGF}$ withdrawal. Proc. Natl. Acad. Sci. USA, 94, 8761-8766.

Benjamin, L.E., Hemo, I. \& Keshet, E. (1998) A plasticity window for blood vessel remodelling is defined by pericyte coverage of the preformed endothelial network and is regulated by PDGF-B and VEGF. Development, 125, 1591-1598.

Brenner, B.M., Troy, J.L. \& Daugharty, T.M. (1971) The dynamics of glomerular ultrafiltration in the rat. J. Clin. Invest., 50, 1776-1780.

Brown, L.F., Berse, B., Tognazzi, K., Manseau, E.J., Van de Water, L., Senger D.R., Donald, R., Dvorak, H.F. \& Rosen, S. (1992) Vascular permeability factor $\mathrm{mRNA}$ and protein expression in human kidney. Kidney Int., 42, 1457-1461.

Carmeliet, P., Ferreira, V., Breier, G., Pollefeyt, S., Kieckens, L., Gertsenstein, M., Fahrig, M., Vandenhoeck, A., Harpal, K., Eberhardt, C., Declercq, C., Pawling, J., Moons, L., Collen, D., Risau, W. \& Nagy, A. (1996) Abnormal blood vessel development and lethality in embryos lacking a single VEGF allele. Nature, 380, 435-439.

Connolly, D.T., Olander, J.V., Heuvelman, D., Nelson, R., Monsell, R., Siegel, N., Haymore, B.L., Leimgruber, R. \& Feder, J. (1989) Human vascular permeability factor. Isolation from U937 cells. J. Biol. Chem., 254, 20017 20024. 
Ericson, A.C., Sjoquist, M., Ulfendahl, H.R. (1982) Heterogeneity in regulation of glomerular function. Acta. Physiol. Scand., 114, 203-209.

Ferrara, N., Carver-Moore, K., Chen, H., Dowd, M., Lu, Lucy., O'Shea, K.S., Powell-Braxton, L., Hillan, K.J. \& Moore, M.W. (1996) Heterozygous embryonic lethality induced by targeted inactivation of the VEGF gene. Nature, 380, 439-442.

Ferrara, N. \& Davis-Smyth, T. (1997) The biology of vascular endothelial growth factor. Endocr. Rev., 18, 4-25.

Ferrara, N., Chen, H., Davis-Smyth, T., Gerber, H.-P., Nguyen, T-N., Peers, D., Chisholm, V., Hillan, K.J. \& Schwall, R.H. (1998) Vascular endothelial growth factor is essential for corpus luteum angiogenesis. Nat. Med., 4, 336-340.

Ferrara, N. (1999) Role of vascular endothelial growth factor in the regulation of angiogenesis. Kidney Int., 56, 794-814.

Gerber, H.P., Hillan, K.J., Ryan, A.M., Kowalski, J., Keller, G.A., Rangell, L., Wright, B.D., Radtke, F., Aguet, M. \& Ferrara, N. (1999) VEGF is required for growth and survival in neonatal mice. Development, 126, 1149-1159.

Gerber, H.P., Vu, T.H., Ryan, A.M., Kowalski, J., Werb, Z. \& Ferrara, N. (1999) VEGF couples hypertrophic cartilage remodeling, ossification and angiogenesis during endochondral bone formation. Nat. Med., 5, 623-628.

Gröne, H.-J., Simon, M. \& Groene, E.F. (1995) Expression of vascular endothelial growth factor in renal vascular disease and renal allografts. J. Pathol., 177, 259-267.

Iruela-Arispe, L., Gordon, K., Hugo, C., Duijvestijn, A.M., Claffey, K.P., Reilly, M., Couser, W.G., Alpers, C.E. \& Johnson, R.J. (1995) Participation of glomerular endothelial cells in the capillary repair of glomerulonephritis. Am. J. Pathol, 147, 17151727.

Ito, S., Arima, S., Ren, Y.L., Juncos, L.A. \& Carretero, O.A. (1993) Endothelium-derived relaxing factor/nitric oxide modulates angiotensisn II action in the isolated microperfused rabbit afferent but not efferent arteriole. J. Clin. Invest., 91, 2012-2019.

Kataoka, H., Takakura, N., Nishikawa, S.,Tsuchida, K., Kodama, H., Kunisada, T., Risau, W., Kita, T. \& Nishikawa, S.I. (1997) Expression of PDGF receptor alpha, c-Kit and Flk-1 genes clustering in mouse chromosome 5 define distinct subsets of nascent mesodermal cells. Develop. Growth. Differ., 39, 729-740.

Kim, K.J., Li, B., Houck, K., Winer, J. \& Ferrara, N. (1992) The vascular endothelial growth factor proteins: Identification of biologically relevant regions by neutralizing monoclonal antibodies. Growth Factors, 7, 53-64.

Kim, K.J., Li, B., Winer, J., Armanini, M., Gillett, N., Phillips, H.S. \& Ferrara, N. (1993) Inhibition of vascular endothelial growth factorinduced angiogenesis suppresses tumor growth in vivo. Nature, 362, 841-844.

Kim, Y.G., Suga, S.I., Kang, D.H., Jefferson, J.A., Mazzali, M., Gordon, K.L., Matsui, K., Breiteneder-Geleff, S., Shankland, S.J., Hughes, J., Kerjaschki, D., Schreiner, G.F. \& Johnson, R.J. (2000) Vascular endothelial growth factor accelerates renal recovery in experimental thrombotic microangiopathy. Kidney Int., 58, 2390-2399.

Kitamoto, Y., Tokunaga, H. \& Tomita, K. (1997) Vascular endothelial growth factor is an essential molecule for mouse kidney development: glomerulogenesis and nephrogenesis. J. Clin. Invest., 99, 2351-2357.

Kitamoto, Y., Matsuo, K. \& Tomita, K. (2001) Different response of urinary excretion of VEGF in patients with chronic and acute renal failure. Kidney Int., 59, 385-386.

Kloth, S., Gerdes, J., Wanke, C. \& Minuth, W.W. (1998) Basic fibroblast growth factor is a morphogenic modulator in kidney vessel development. Kidney Int., 53, 970-978.

Marti, H. \& Risau, W. (1998) Systemic hypoxia changes the organ-specific distribution of vascular endothelial growth factor and its receptors. Proc. Natl. Acad. Sci. USA, 95, 15809 15814.

Miller, L.W., Redfield, M.M. \& Burnett, J.C.J. (1989) Integrated cardiac, renal, and endocrine action of endothelin. J. Clin. Invest., 83, 317-320.

Okada, N. \& Okada, H. (1978) Activation of complement by spontaneous leukemic cells of AKR mice. Int. J. Cancer, 22, 282-287.

Ostendorf, T., Kunter, U., Eitner, F., Loos, A., Regele, H., Kerjaschki, D., Henninger, D.D., Janjic, N. \& Floege, J. (1999) VEGF 165 mediates glomerular endothelial repair. $J$. Clin. Invest., 104, 913-923.

Sato, Y., Abe, M., Tanaka, K., Iwasaka, C., Oda, N., Kanno, S., Oikawa, M., Nakano, T. \& Igarashi, T. (2000) Signal transduction and tran- 
scriptional regulation of angiogenesis. $A d v$. Exp. Med. Biol., 476, 109-115.

Senger, D.R., Galli, S.J., Dvorak, A.M., Perruzzi, C.A., Harvey, V.S. \& Dvorak, H.F. (1983) Tumor cells secrete a vascular permeability factor that promotes accumulation of ascites fluid. Science, 219, 983-985.

Shulman, K., Rosen, S., Tognazzi, K., Manseau, E.J. \& Brown, L.F. (1996) Expression of vascular permeability factor (VPF/VEGF) is altered in many glomerular diseases. J. Am. Soc. Nephrol., 7, 661-666.

Shweiki, D., Itin, A., Soffer, D. \& Keshet, E. (1992) Vascular endothelial growth factor induced by hypoxia may mediate hypoxia-initiated angiogenesis. Nature, 359, 843-845.

Simon, M., Gröne, H., Jöhren, O., Kullmer, J., Plate,
K.H., Risau, W. \& Fuchs, E. (1995) Expression of vascular endothelial growth factor and its receptors in human renal ontogenesis and in adult kidney. Am. J. Physiol., 268, F240F250.

Takeshita, S., Zheng, L., Brogi, E., Kearney, M., Pu, L.Q., Bunting, S., Ferrara, N., Symes, J.F. \& Isner, J.M. (1994) Therapeutic angiogenesis. J. Clin. Invest., 93, 662-670.

Tolins, J.P., Palmer, R.M., Moncada, S. \& Raij, L. (1990) Role of endothelium-derived relaxing factor in regulation of renal hemodynamic responses. Am. J. Physiol., 258, H655-H662.

Tufro, A., Norwood, V.F., Carey, R.M. \& Gomez, R.A. (1999) Vascular endothelial growth factor induces nephrogenesis and vasculogenesis. J. Am. Soc. Nephrol., 10, 2125-2134. 